\title{
ANALISIS KERUSAKAN JALAN MENGGUNAKAN METODE BINA MARGA PADA JALAN RAJAWALI KOTA PALANGKA RAYA
}

\author{
Bangun Siagin ${ }^{1}$, Desi Riani ${ }^{2}$ dan Salonten ${ }^{3}$ \\ ${ }^{123}$ Program Studi Teknik Sipil, Fakultas Teknik, Universitas Palangka Raya \\ E-mail: bangunsiagian65@gmail.com¹, desiriani@jts.upr.ac.id² dan \\ salonten@jts.upr.ac.id ${ }^{3} /$ HP. +6282313282089 ${ }^{1}$
}

\begin{abstract}
ABSTRAK
Pemeliharaan jalan merupakan upaya untuk meningkatkan kembali kondisi jalan yang layak secara fungsional serta layak secara struktural. Bentuk pemeliharaan jalan tergantung dari hasil penilaian kondisi kerusakan permukaan jalan yang terjadi pada jalan tersebut. Penelitian tersebut bertujuan untuk mengetahui jenis-jenis kerusakan permukaan jalan, nilai kerusakan jalan dan urutan prioritas penanganan pada Jalan Rajawali dengan menggunakan Metode Bina Marga 1990. Setelah dilakukan pengukuran, Jalan Rajawali memiliki panjang jalan \pm 5.765 meter, adapun data primer yang dibutuhkan yaitu data inventaris jalan, data kerusakan jalan dan data volume lalulintas sedangkan data sekunder yang dibutuhkan data umur jalan dan peta lokasi penelitian. Hasil analisis pada Jalan Rajawali diketahui bahwa jenis-jenis kerusakan yang terjadi pada ruas jalan tersebut yaitu tambalan, retak, lubang, alur, bergelombang, amblas dan pelepasan butir. Nilai kerusakan jalan pada masingmasing segmen yaitu $(15,15,15,10$ dan 9$)$. Untuk urutan prioritasnya yaitu segmen I, II, III, termasuk pemeliharaan berkala dan segmen IV, V termasuk pemeliharaan rutin.
\end{abstract}

\section{Kata kunci : Jenis Kerusakan Jalan, Nilai Kerusakan, Urutan Prioritas.}

\section{ABSTRACT}

Road maintenance is an effort to improve road conditions that are functionally and structurally feasible. The form of road maintenance depends on the results of the assessment of the road surface damage that occurs on the road. The research aims to determine the types of road surface damage, the value of road damage and the priority order of handling on Jalan Rajawali using the 1990 Bina Marga Method. After the measurement, Jalan Rajawali has a road length of \pm 5,765 meters, while the primary data required is inventory data. roads, road damage data and traffic volume data, while secondary data is needed road age data and a map of the research location. The results of the analysis on Jalan Rajawali revealed that the types of damage that occurred on the road were patches, cracks, holes, grooves, bumps, subsidence and grain release. The value of road damage in each segment were (15, 15, 15, 10 and 9). The order of priority was segment I, II, III, include periodic maintenance and segment IV, $V$ include routine maintenance. Keywords: Type of Damage to Roads, Value of Damage, Order of Priority., Order of Priority. 


\section{PENDAHULUAN}

\section{Latar Belakang}

Jalan merupakan prasarana transportasi bagi masyarakat dan berperan penting untuk pengembangan suatu daerah sehingga jalan yang ada diharapkan dapat memberikan pelayanan baik bagi seluruh pengguna jalan. Ruas Jalan Rajawali ramai dilalui kendaraan baik kendaraan ringan, kendaraan berat, sepeda motor maupun sepeda. Sehingga Jalan Rajawali mengalami kerusakan dan tingkat pelayanan pada Jalan Rajawali menurun, hal tersebut yang menjadi latar belakang memilih judul beserta lokasi penelitian, untuk penilaian kondisi pada Jalan Rajawali menggunakan metode Bina Marga, agar mendapatkan hasil yang lebih teliti maka ruas Jalan Rajwali ( \pm 5.765 meter) dibagi menjadi 5 segmen sehingga data kerusakan jalan dan data LHR (Lalulintas harian rata-rata) jalan yang didapat lebih rinci saat memproses data dilakukan.

\section{Tujuan Penelitian:}

1. Mengetahui jenis kerusakan yang terjadi di Jalan Rajawali.

2. Mengetahui Nilai Kerusakan dari setiap jenis kerusakan.

3. Mengetahui urutan prioritas perbaikan jalan pada Jalan Rajawali.

\section{Batasan masalah:}

1. Lokasi penelitian dilakukan di sepanjang Jalan Rajawali.

2. Penelitian yang dilakukan tidak memuat mengenai perencanaan perkerasannya.

3. Penelitian tidak memuat mengenai penanganan kerusakan yang terjadi.

\section{METODE PENELITIAN}

\section{Lokasi Penelitian}

Penelitian dilakukan pada sepanjang Jalan Rajawali $( \pm 5.765 \mathrm{~m})$ dan dibagi menjadi lima segmen.

\section{Waktu Penelitian}

Penelitian ini dilakukan selama 2 minggu pada pagi, siang dan sore dengan periode waktu 16 jam.

\section{Tahapan Penelitian}

Tahapan dalam penelitian ini diuraikan sebagai berikut

1. Survei Inventarisasi jalan yaitu mempersiapkan peralatan survei seperti Form survei, meteran, kamera, dan alat tulis.

2. Survei Pendahuluan yaitu melakukan pengukuran jalan untuk mengetahui panjang dan lebar jalan pada setiap segmen.

3. Survei kerusakan jalan melaksanakan survei untuk mendapatkan data LHR dan data kerusakan jalan.

4. Pengumpulan Data

Mengumpulkan data primer dan data sekunder yang diperlukan dalam analisis data. 
JURNAL KACAPURI

JURNAL KEILMUAN TEKNIK SIPIL

5. Analisis Data dan Pembahasan

Melakukan analisis perhitungan luas jenis kerusakan, nilai kerusakan dan urutan prioritas terhadap data primer dan sekunder yang sudah didapat.

6. Kesimpulan dan Saran

Pengambilan kesimpulan dan saran berdasarkan hasil analisis perhitungan data dari penelitian yang dilakukan.

\section{HASIL \& PEMBAHASAN}

\section{Lokasi Penelitian}

1. Sketsa pembagian Ruas Jalan Rajawali

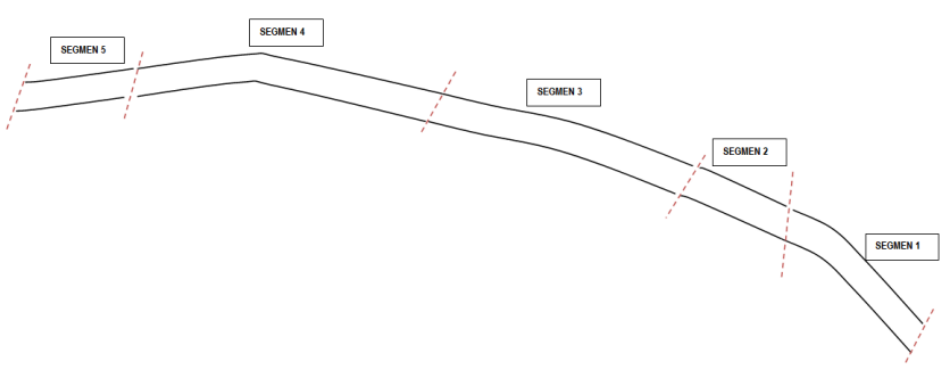

Sumber: Google Maps, (2021)

Berikut pembagian segmen dan penjelasan mengenai data inventarisasi jalan yang sudah dibagi menjadi 5 Segmen sebagai berikut:

1. Segmen 1: Pertigaan Jalan Beliang-Rajawali sampai Perempatan Jalan GarudaRajawali (STA 0+000 - STA 0+861).

2. Segmen 2: Perempatan Jalan Garuda-Rajawali sampai Perempatan Jalan TingangRajawali (STA 0+861 - STA 1+417).

3. Segmen 3: Perempatan Jalan Tingang-Rajawali sampai Perempatan Jalan BadakRajawali (STA 1+417 - STA 3+021).

4. Segmen 4: Perempatan Jalan Badak-Rajawali sampai Perempatan Jalan Hiu PutihRajawali (STA 3+021 - STA 5+023).

5. Segmen 5: Perempatan Jalan Badak-Rajawali sampai Pertigaan Jalan Mahir Mahar-Rajawali (STA 5+023 - STA 5+765).

Jenis-jenis kerusakan

Jenis kerusakan yang terjadi pada lokasi penelitian dapat dilihat pada Tabel 4 : 
Tabel 1. Jenis-Jenis Kerusakan Yang Terjadi

\begin{tabular}{|c|c|c|c|c|}
\hline Segmen I & Segmen II & Segmen III & Segmen IV & Segmen V \\
\hline Tambalan & Tambalan & Tambalan & Retak & Retak \\
\hline Retak & Retak & Retak & Lubang & Lubang \\
\hline Lubang & Lubang & Lubang & Bergelombang & Bergelombang \\
\hline Alur & Bergelombang & Bergelombang & Amblas & \multirow{3}{*}{ Amblas } \\
\hline Bergelombang & Amblas & Amblas & \multirow{2}{*}{$\begin{array}{l}\text { Pelepasan } \\
\text { butir }\end{array}$} & \\
\hline $\begin{array}{l}\text { Pelepasan } \\
\text { butir }\end{array}$ & $\begin{array}{l}\text { Pelepasan } \\
\text { butir }\end{array}$ & $\begin{array}{l}\text { Pelepasan } \\
\text { butir }\end{array}$ & & \\
\hline
\end{tabular}

Sumber: Hasil Survei, (2019)

\section{Data Kerusakan Jalan}

Setelah dilakukan penelitian maka didapat data kerusakan jalan setiap segmen dapat dilihat pada tabel berikut:

Tabel 2. Luas Jenis Kerusakan Segmen I Tahun 2019

\begin{tabular}{|c|c|c|}
\hline \multicolumn{3}{|c|}{ Segmen I } \\
\hline $\begin{array}{c}\text { Jenis } \\
\text { Kerusakan }\end{array}$ & $\begin{array}{l}\text { Luas Jalan } \\
\text { Rusak }\left(\mathbf{m}^{2}\right)\end{array}$ & $\begin{array}{c}\text { Luas Jalan } \\
\text { Total }\left(\mathbf{m}^{2}\right)\end{array}$ \\
\hline Tambalan & 0,495 & $4.907,7$ \\
\hline Retak & 70,25 & $4.907,7$ \\
\hline Lubang & 4,572 & $4.907,7$ \\
\hline Alur & 0,44 & $4.907,7$ \\
\hline Bergelombang & 188,515 & $4.907,7$ \\
\hline Amblas & 0 & $4.907,7$ \\
\hline $\begin{array}{c}\text { Pelepasan } \\
\text { Butir }\end{array}$ & $1.569,835$ & $4.907,7$ \\
\hline
\end{tabular}

Sumber: Hasil Perhitungan, (2019)

Tabel 3. Luas Jenis Kerusakan Segmen II Tahun 2019

\begin{tabular}{|c|c|c|}
\hline \multicolumn{3}{|c|}{ Segmen II } \\
\hline $\begin{array}{c}\text { Jenis } \\
\text { Kerusakan }\end{array}$ & $\begin{array}{c}\text { Luas Jalan } \\
\left.\text { Rusak } \mathbf{( m}^{\mathbf{2}}\right)\end{array}$ & $\begin{array}{c}\text { Luas Jalan } \\
\text { Total } \mathbf{( m}^{\mathbf{2}} \mathbf{}\end{array}$ \\
\hline Tambalan & 9,649 & 3391,6 \\
\hline Retak & 16,872 & 3391,6 \\
\hline Lubang & 1,502 & 3391,6 \\
\hline Alur & 0 & 3391,6 \\
\hline Bergelombang & 5,04 & 3391,6 \\
\hline Amblas & 3,645 & 3391,6 \\
\hline $\begin{array}{c}\text { Pelepasan } \\
\text { Butir }\end{array}$ & 1351 & 3391,6 \\
\hline
\end{tabular}

Sumber: Hasil Perhitungan, (2019) 
Tabel 4. Luas Jenis Kerusakan Segmen III Tahun 2019

\begin{tabular}{|c|c|c|}
\hline \multicolumn{3}{|c|}{ Segmen III } \\
\hline $\begin{array}{c}\text { Jenis } \\
\text { Kerusakan }\end{array}$ & $\begin{array}{l}\text { Luas Jalan } \\
\text { Rusak }\left(\mathbf{m}^{2}\right)\end{array}$ & $\begin{array}{c}\text { Luas Jalan } \\
\text { Total }\left(\mathbf{m}^{2}\right)\end{array}$ \\
\hline Tambalan & 84,428 & 9463,6 \\
\hline Retak & 134,754 & 9463,6 \\
\hline Lubang & 3,651 & 9463,6 \\
\hline Alur & 0 & 9463,6 \\
\hline Bergelombang & 87,475 & 9463,6 \\
\hline Amblas & 4,538 & 9463,6 \\
\hline $\begin{array}{c}\text { Pelepasan } \\
\text { Butir }\end{array}$ & 1225,888 & 9463,6 \\
\hline
\end{tabular}

Sumber: Hasil Perhitungan, (2019)

Tabel 5. Luas Jenis Kerusakan Segmen IV Tahun 2019

\begin{tabular}{|c|c|c|}
\hline \multicolumn{3}{|c|}{ Segmen IV } \\
\hline $\begin{array}{c}\text { Jenis } \\
\text { Kerusakan }\end{array}$ & $\begin{array}{c}\text { Luas Jalan } \\
\text { Rusak }\left(\mathbf{m}^{\mathbf{2}}\right)\end{array}$ & $\begin{array}{c}\text { Luas Jalan } \\
\text { Total } \mathbf{( m}^{\mathbf{2}} \mathbf{)}\end{array}$ \\
\hline Tambalan & 0 & 11011 \\
\hline Retak & 1,383 & 11011 \\
\hline Lubang & 5,943 & 11011 \\
\hline Alur & 0 & 11011 \\
\hline Bergelombang & 1,575 & 11011 \\
\hline Amblas & 50,016 & 11011 \\
\hline $\begin{array}{c}\text { Pelepasan } \\
\text { Butir }\end{array}$ & 45,5 & 11011 \\
\hline
\end{tabular}

Sumber: Hasil Perhitungan, (2019)

Tabel 6. Luas Jenis Kerusakan Segmen V Tahun 2019

\begin{tabular}{|c|c|c|}
\hline \multicolumn{3}{|c|}{ Segmen V } \\
\hline $\begin{array}{c}\text { Jenis } \\
\text { Kerusakan }\end{array}$ & $\begin{array}{c}\text { Luas Jalan } \\
\text { Rusak }\left(\mathbf{m}^{\mathbf{2}}\right)\end{array}$ & $\begin{array}{c}\text { Luas Jalan } \\
\left.\text { Total } \mathbf{( m}^{\mathbf{2}}\right)\end{array}$ \\
\hline Tambalan & 0 & 2819,6 \\
\hline Retak & 24,82 & 2819,6 \\
\hline Lubang & 3,604 & 2819,6 \\
\hline Alur & 0 & 2819,6 \\
\hline Bergelombang & 434,66 & 2819,6 \\
\hline Amblas & 90,72 & 2819,6 \\
\hline $\begin{array}{c}\text { Pelepasan } \\
\text { Butir }\end{array}$ & 0 & 2819,6 \\
\hline
\end{tabular}

Sumber: Hasil Perhitungan, (2019) 
Nilai Kerusakan Jalan (Nr)

Nilai kerusakan jalan ( $\mathrm{Nr}$ ) merupakan jumlah total dari setiap jumlah kerusakan pada suatu ruas jalan.

Tabel 7. Nilai Kerusakan Segmen I

\begin{tabular}{|c|c|c|}
\hline \multicolumn{3}{|c|}{ Segmen I } \\
\hline Jenis Kerusakan & Np \% & Np \\
\hline Tambalan & 0,01 & 2 \\
\hline Retak & 1,43 & 2 \\
\hline Lubang & 0,09 & 2 \\
\hline Alur & 0,01 & 2 \\
\hline Bergelombang & 3,84 & 2 \\
\hline Amblas & 0 & 0 \\
\hline Pelepasan Butir & 31,99 & 5 \\
\hline Nr & $\mathbf{1 5}$ \\
\hline
\end{tabular}

Sumber: Hasil Perhitungan, (2019)

Tabel 8. Nilai Kerusakan Segmen II

\begin{tabular}{|c|c|c|}
\hline \multicolumn{3}{|c|}{ Segmen II } \\
\hline Jenis Kerusakan & Np \% & Np \\
\hline Tambalan & 0,28 & 2 \\
\hline Retak & 0,5 & 2 \\
\hline Lubang & 0,04 & 2 \\
\hline Alur & 0 & 0 \\
\hline Bergelombang & 0,15 & 2 \\
\hline Amblas & 0,11 & 2 \\
\hline Pelepasan Butir & 39,83 & 5 \\
\hline \multicolumn{2}{|c|}{} & $\mathbf{1 5}$ \\
\hline
\end{tabular}

Sumber: Hasil Perhitungan, (2019)

Tabel 9. Nilai Kerusakan Segmen III

\begin{tabular}{|c|c|c|}
\hline \multicolumn{3}{|c|}{ Segmen III } \\
\hline Jenis Kerusakan & Np \% & Np \\
\hline Tambalan & 0,89 & 2 \\
\hline Retak & 1,42 & 2 \\
\hline Lubang & 0,04 & 2 \\
\hline Alur & 0 & 0 \\
\hline Bergelombang & 0,92 & 2 \\
\hline Amblas & 0,05 & 2 \\
\hline Pelepasan Butir & 12,95 & 3 \\
\hline \multicolumn{2}{|c|}{ Nr } & $\mathbf{1 5}$ \\
\hline
\end{tabular}

Sumber: Hasil Perhitungan, (2019) 
Tabel 10. Nilai Kerusakan Segmen IV

\begin{tabular}{|c|c|c|}
\hline \multicolumn{3}{|c|}{ Segmen IV } \\
\hline Jenis Kerusakan & Np \% & Np \\
\hline Tambalan & 0 & 0 \\
\hline Retak & 0,01 & 2 \\
\hline Lubang & 0,05 & 2 \\
\hline Alur & 0 & 0 \\
\hline Bergelombang & 0,01 & 2 \\
\hline Amblas & 0,45 & 2 \\
\hline Pelepasan Butir & 0,41 & 2 \\
\hline \multicolumn{2}{|c|}{ Nr } & $\mathbf{1 0}$ \\
\hline
\end{tabular}

Sumber: Hasil Perhitungan, (2019)

Tabel 11. Nilai Kerusakan Segmen V

\begin{tabular}{|c|c|c|}
\hline \multicolumn{3}{|c|}{ Segmen V } \\
\hline Jensi Kerusakan & Np \% & Np \\
\hline Tambalan & 0 & 0 \\
\hline Retak & 0,88 & 2 \\
\hline Lubang & 0,13 & 2 \\
\hline Alur & 0 & 0 \\
\hline Bergelombang & 15,42 & 3 \\
\hline Amblas & 3,22 & 2 \\
\hline Pelepasan Butir & 0 & 0 \\
\hline Nr & $\mathbf{9}$ \\
\hline
\end{tabular}

Sumber: Hasil Perhitungan, (2019)

\section{Nilai kelas jalan}

Nilai kelas jalan dapat diketahui setelah LHR dari masing-masing segmen sudah didapat.

Tabel 12. Nilai Kelas Jalan

\begin{tabular}{|c|c|c|c|c|c|}
\hline Segmen & $\begin{array}{c}\text { Sepeda } \\
\text { Motor } \\
\text { (MC) }\end{array}$ & $\begin{array}{c}\text { Kendaraan } \\
\text { Ringan } \\
\text { (LV) }\end{array}$ & $\begin{array}{c}\text { Kendaraan } \\
\text { Berat } \\
\text { Menengah } \\
\text { (MHV) }\end{array}$ & $\begin{array}{c}\text { LHR } \\
\text { (smp/hari) }\end{array}$ & $\begin{array}{c}\text { Nilai } \\
\text { Kelas } \\
\text { Jalan }\end{array}$ \\
\hline I & 8088,396 & 3525,857 & 96,571 & 11710,825 & 6 \\
\hline II & 6659,486 & 3580,714 & 107,900 & 10348,100 & 6 \\
\hline III & 8576,929 & 4027,714 & 125,543 & 12730,186 & 6 \\
\hline IV & 9139,929 & 4093,286 & 128,886 & 13362,100 & 6 \\
\hline V & 2865,286 & 695,429 & 111,800 & 3672,514 & 5 \\
\hline
\end{tabular}

Sumber: Hasil Survei, (2019) 
Nilai kondisi jalan

Nilai kondisi setiap segmen dapat dihitung setalah mengetahui nilai persentase kerusakan jalan yang terjadi pada ruas Jalan Rajawali.

Tabel 13. Nilai Kondisi Jalan

\begin{tabular}{|c|c|}
\hline Segmen & $\begin{array}{c}\text { Nilai } \\
\text { kondisi } \\
\text { jalan }\end{array}$ \\
\hline $\begin{array}{c}\text { I (Ruas Jalan Beliang-Jalan } \\
\text { Garuda) }\end{array}$ & 5 \\
\hline $\begin{array}{c}\text { II (Ruas Jalan Garuda- } \\
\text { Tingang) }\end{array}$ & 5 \\
\hline $\begin{array}{c}\text { III (Ruas Jalan Tingang- } \\
\text { Jalan Badak) }\end{array}$ & 5 \\
\hline $\begin{array}{c}\text { IV (Ruas Jalan Badak- } \\
\text { Jalan Hiu Putih) }\end{array}$ & 3 \\
\hline $\begin{array}{c}\text { V (Ruas Jalan Hiu Putih- } \\
\text { Jalan Mahir Mahar) }\end{array}$ & 3 \\
\hline
\end{tabular}

Sumber: Hasil Perhitungan, (2019)

\section{Urutan Prioritas (UP)}

a. Urutan prioritas 0-3, menandakan bahwa jalan harus dimasukkan dalam program peningkatan.

b. Urutan prioritas 4-6, menandakan bahwa jalan perlu dimasukkan dalam program pemeliharaan berkala.

c. Urutan Prioritas $\geq 7$, menandakan bahwa jalan tersebut cukup dimasukkan dalam program pemeliharaan rutin.

Tabel 14. Urutan Prioritas

\begin{tabular}{|c|c|c|c|l|}
\hline Segmen & $\begin{array}{c}\text { Nilai } \\
\text { kelas } \\
\text { jalan }\end{array}$ & $\begin{array}{c}\text { Nilai } \\
\text { kondisi } \\
\text { jalan }\end{array}$ & $\begin{array}{c}\text { Urutan } \\
\text { prioritas } \\
\text { (UP) }\end{array}$ & Keterangan \\
\hline I & 6 & 5 & 6 & $\begin{array}{l}\text { Pemeliharaan } \\
\text { Berkala }\end{array}$ \\
\hline II & 6 & 5 & 6 & $\begin{array}{l}\text { Pemeliharaan } \\
\text { Berkala }\end{array}$ \\
\hline III & 6 & 5 & 6 & $\begin{array}{l}\text { Program } \\
\text { Berkala }\end{array}$ \\
\hline IV & 6 & 4 & 7 & $\begin{array}{l}\text { Pemeliharaan } \\
\text { Rutin }\end{array}$ \\
\hline V & 5 & 3 & 9 & $\begin{array}{l}\text { Pemeliharaan } \\
\text { Rutin }\end{array}$ \\
\hline
\end{tabular}

Sumber: Hasil Perhitungan, (2019) 


\section{PENUTUP}

\section{Kesimpulan}

1. Jenis-jenis kerusakan yang terjadi pada sepanjang Jalan Rajawali yaitu:

a. Segmen I: Jenis kerusakan yang terjadi adalah tambalan, retak, lubang, alur, bergelombang dan pelepasan butir. Dengan kerusakan pelepasan butir luas kerusakan 31,99\% yaitu kerusakan dengan persentase terbesar, kerusakan retak, kerusakan bergelombang luas kerusakan 3,84\% yaitu kerusakan dengan persentase terkecil.

b. Segmen II: Jenis kerusakan yang terjadi adalah tambalan, retak, lubang, amblas, bergelombang dan pelepasan butir. Dengan kerusakan pelepasan butir luas kerusakan 39,83\% yaitu kerusakan dengan persentase terbesar, kerusakan retak luas kerusakan $0,50 \%$ yaitu kerusakan dengan persentase terkecil.

c. Segmen III: Jenis kerusakan yang terjadi adalah tambalan, retak, lubang, amblas, bergelombang dan pelepasan butir. Dengan kerusakan pelepasan butir luas kerusakan 12,95\% yaitu kerusakan dengan persentase terbesar, kerusakan retak, kerusakan bergelombang dan kerusakan tambalas luas kerusakan 0,89\% yaitu kerusakan dengan persentase terkecil.

d. Segmen IV: Jenis kerusakan yang terjadi adalah retak, lubang, amblas, bergelombang dan pelepasan butir. Dengan kerusakan amblas luas kerusakan $0,45 \%$ yaitu kerusakan dengan persentase terbesar,dan kerusakan pelepasan butir luas kerusakan $0,41 \%$ yaitu kerusakan dengan persentase terkecil.

e. Segmen V: Jenis kerusakan yang terjadi adalah retak, lubang, amblas dan bergelombang. Dengan kerusakan bergelombang luas kerusakan 15,42\% yaitu kerusakan dengan persentase terbesar, kerusakan amblas, dan kerusakan retak dan kerusakan tambalas luas kerusakan $0,88 \%$ yaitu kerusakan dengan persentase terkecil.

2. Nilai kerusakan masing-masing pada ruas Jalan Rajawali yaitu pada segmen I (15), segmen II (15), segmen III (15), segmen IV (10) dan segmen V (9).

3. Urutan prioritas perbaikan jalan pada Jalan Rajawali setelah dilakukan analisis yaitu segmen I, II, III, termasuk dalam pemeliharan berkala sedangkan segmen IV, $\mathrm{V}$ termasuk dalam pemeliharaan rutin.

\section{Saran}

1. Segera melakukan perbaikan jalan pada segmen I, II, III agar kerusakan yang gterdapat pada segmen tersebut tidak semakin parah sehingga menurunkan tingkat pelayanan jalan pada segmen tersebut.

2. Pengukuran kerusakan sebaiknya dilakukan pada malam hari untuk mengurangi kesalahan pengukuran pada siang hari saat lalulintas sangat padat.

3. Saat melakukan survei kerusakan harus dilakukan dengan cermat untuk pengukuran dimensi kerusakan terhadap jenis kerusakan yang ada karena sangat berpengaruh terhadap pembahasan. 


\section{DAFTAR PUSTAKA}

Anonim. 1983. Manual Pemeliharaan Jalan No. 03/MN/B/1983. Jakarta: Dirjen Bina Marga DPU.

Anonim. 1990. Tata Cara Penyusunan Program Pemeliharaan Jalan Kota, Jakarta: Dirjen Bina Marga DPU.

Anonim. 1997. Manual Kapasitas Jalan Indonesia (MKJI), Jakarta: Dirjen Bina Marga DPU.

Bolla, M.E. 2012. Perbandingan Metode Bina Marga dan Metode PCI (Pavement Condition Index) Dalam Penilaian Kondisi Perkerasan Jalan (Studi Kasus Ruas Jalan Kaliurang, Kota Malang). Jurnal Teknik Sipil, Vol 1 No. 3, 104-116, Malang.

Handoyo, A.H. 2016. Analisis Kerusakan Jalan Perkotaan Menggunakan Metode Bina Marga (Studi Kasus Jalan Perkotaan Kabupaten Wonosobo). Skripsi Universitas Muhamamadiyah Purworejo, Purworejo.

Hardiyatmo, H.C. 2015. Pemeliharaan Jalan Raya, Edisi Ke II. Yogyakarta: Gadjah Mada University Press. 